SAT0150

EFFICACY OF TOCILIZUMAB FOR SUPPRESSING RADIOGRAPHIC PROGRESSION OF CERVICAL LESIONS IN PATIENTS WITH RHEUMATOID ARTHRITIS COMPARISON WITH METHOTREXATE; THREE YEARS OF FOLLOW-UP A MULTICENTER REGISTRY STUDY

Yasuhide Kanayama ${ }^{1}$, Toshihisa Kojima ${ }^{2}$, Yuji Hirano ${ }^{3}$, Yuichiro Yabe ${ }^{4}$, Nobunori Takahashi ${ }^{2}$, Naoki Ishiguro' ${ }^{2}$, TBCR study group. ${ }^{1}$ Toyota Kosei Hospital, Orthopedic Surgery and Rheumatology, Toyota, Japan; ${ }^{2}$ Nagoya University Graduate School of Medicine, Orthopedic Surgery, Nagoya, Japan; ${ }^{3}$ Toyohashi Municipal Hospital, Rheumatology, Toyohashi, Japan; ${ }^{4} \mathrm{JCHO}$ Tokyo Shinjuku Medical Center, Rheumatology, Tokyo, Japan

Background: Cervical lesions are known to occur at high frequency as a complication of rheumatoid arthritis (RA). Treatment with biological agents are more clinically effective than the DMARDs that were in use previously, in particular, with their efficacy in suppressing joint destruction having been emphasized. We reported the efficacy of infliximab, anti-tumor necrosis factor antibodies for suppressing the radiographic progression of RA cervical lesions at ACR2009, EULAR2010, 11, 12, 13, 14, 16 and 18. However there is still few studies of efficacy of against RA cervical lesions of Tocilizumab (TCZ), anti-interleukin 6 receptor antibody.

Objectives: To evaluate the efficacy of TCZ for suppressing the radiographic progression of RA cervical lesions comparison with MTX for 3 years.

Methods: We used TCZ or MTX for treating Japanese patients with active RA who fulfilled the ACR criteria in 1987. The final study cohort of each 50 and 75 patients received continuous TCZ and MTX treatment for at least 3 years. For evaluation of cervical lesions, the atlanto-dental interval (ADI), the space available for the spinal cord (SAC), and the Ranawat value were measured by plain lateral radiographs in the flexion position, at initiation and Year 1,2 and 3 .

Results: In the patients receiving TCZ $(n=50)$ and MTX $(n=75)$, the number of female were each $38(76 \%)$ and $52(69 \%)$ cases $(p=0.416)$. The mean age was $58.7 \pm 13.0$ and $63.6 \pm 11.0$ years old $(\mathrm{p}=0.046)$; disease duration was $7.7 \pm 7.8$ and $8.0 \pm 9.5$ years $(p=0.247)$ and the mean dose of MTX was $9.2 \pm 3.6$ and $8.2 \pm 2.9 \mathrm{mg} / \mathrm{w}(\mathrm{p}=0.146)$. Clinical findings related to RA were as follows; CRP $4.2 \pm 3.4$ and $1.7 \pm 2.3$ $\mathrm{mg} / \mathrm{dl}(\mathrm{p}<0.001) ; \mathrm{ESR} 55.0 \pm 24.0$ and $31.9 \pm 21.8 \mathrm{~mm} / \mathrm{h}(\mathrm{p}<0.001) ; \mathrm{MMP} 3$ $401 \pm 311$ and $223 \pm 350 \mathrm{ng} / \mathrm{ml}(\mathrm{p}<0.001)$; the number of RF-positive 40 $(80 \%)$ and $60(80 \%)$ cases $(\mathrm{p}=0.999)$; DAS28-ESR $5.45 \pm 0.98$ and $4.30 \pm$ $1.38(\mathrm{p}<0.001) ; \mathrm{ADI} 2.9 \pm 1.7$ and $2.6 \pm 1.6 \mathrm{~mm}(\mathrm{p}=0.335)$; $\mathrm{SAC} 18.9 \pm$ 2.7 and $20.8 \pm 2.5 \mathrm{~mm}(\mathrm{p}<0.001)$ and Ranawat value $15.2 \pm 1.6$ and 16.0 $\pm 1.5 \mathrm{~mm} \quad(\mathrm{p}=0.008)$.

The respective changes in cervical lesion parameters after 3 years were as follows: ADI: $0.46 \pm 0.79$ and $0.71 \pm 0.80 \mathrm{~mm}(p=0.044)$; SAC: $-0.34 \pm 0.63$ and $-0.63 \pm 0.82 \mathrm{~mm}(\mathrm{p}=0.027)$; and Ranawat value: $-0.32 \pm 0.59$ and $-0.44 \pm 0.66 \mathrm{~mm}(p=0.295)$ between TCZ and MTX patients (Fig.1).

The numbers of patients who did not showed progression in ADI, SAC and Ranawat value were each $34(68 \%)$ vs $37(49 \%)$ cases $(\mathrm{p}=0.039) ; 37$ $(74 \%)$ vs $40(53 \%) \quad$ cases $(p=0.020)$ and $37(74 \%)$ vs $49(65 \%)$ cases $(p=0.306)$ after 3 years. Also the number who was able to suppress progression in all three parameters were each 34 cases $(68 \%)$ receiving TCZ and 37 cases (49\%) receiving MTX ( $\mathrm{p}=0.039)$ after 3 years (Fig.2). Conclusion: This study suggested that TCZ treatment can be used to suppress the progression of RA cervical lesions more than MTX treatment.

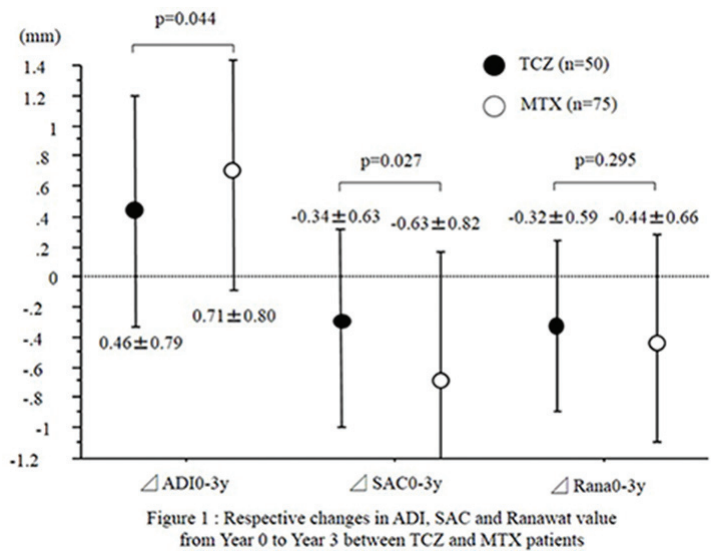

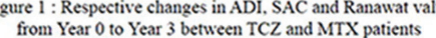
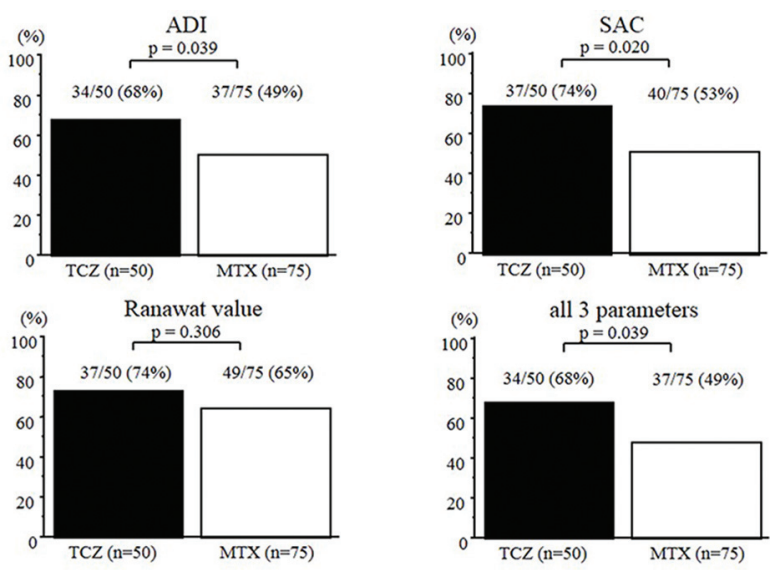

Figure 2 : The rate of patients who did not showed progression in ADI, $\mathrm{SAC}$, Ranawat value and all three parameters after 3 years

Disclosure of Interests: Yasuhide Kanayama: None declared, Toshihisa Kojima Grant/research support from: Chugai Pharmaceutical (Investigator Initiated Study), Novartis, Nippon Kayaku, Eli Lilly, Eisai, Speakers bureau: Chugai Pharmaceutical, Takeda Pharmaceutical, Pfizer, Eli Lilly Japan, Bristol Myers Squibb, Ono Pharmaceutical, Daiichi Sankyo, Astelas, UCB, Janssen Pharmaceutical, Tanabe Mitsubishi, Yuji Hirano: None declared, Yuichiro Yabe: None declared, Nobunori Takahashi Speakers bureau: AbbVie, Bristol-Myers Squibb, Chugai, Eisai, Mitsubishi Tanabe, and Pfizer. YS has received speakers' fees from Astellas, Bristol-Myers Squibb, and Ono, Naoki Ishiguro Grant/research support from: AbbVie, Asahi Kasei, Astellas, Chugai, Daiichi-Sankyo, Eisai, Kaken, Mitsubishi Tanabe, Otsuka, Pfizer, Takeda, and Zimmer Biomet, Consultant for: Ono, Speakers bureau: Astellas, Bristol-Myers Squibb, Daiichi-Sankyo, Eli Lilly, Pfizer, and Taisho Toyama

DOI: 10.1136/annrheumdis-2019-eular.4027

\section{SAT0151 TIME TO INITIATION OF BIOLOGIC DISEASE- MODIFYING ANTIRHEUMATIC DRUGS IN THE FRENCH COHORT ESPOIR}

Joanna Kedra ${ }^{1}$, Benjamin Granger $^{2}$, Stephanie Emilie ${ }^{3}$, Cecile Gaujoux-Viala ${ }^{4}$, Anne-Christine Rat ${ }^{5}$, Bernard Combe ${ }^{6}$, Bruno Fautrel ${ }^{3} .{ }^{1}$ Sorbonne Université, Institut Pierre Louis d'Epidémiologie et de Santé Publique (iPLESP), UMR S1136, Paris, France; ${ }^{2}$ AP-HP, Pitié Salpêtrière hospital, Biostatistics department, Paris, France; ${ }^{3} A P-H P$, Pitié Salpêtrière hospital, Rheumatology department, Paris, France; ${ }^{4}$ Nîmes University Hospital, Nimes, France; ${ }^{5}$ University of Lorraine, EA 4360 APEMAC, and Rheumatology department, Nancy, France; ${ }^{6}$ Montpellier University, CHU Montpellier, Rheumatology Dept, Montpellier, France

Background: Access to biologic Disease-Modifying Anti-Rheumatic Drugs (DMARDs) of early rheumatoid arthritis (RA) patients is highly variable across countries and may depend on patient characteristics, disease expression, physicians behaviors as well as care organization in the patient region of living.

Objectives: 1) To assess the time to initiation of bDMARDs in the French cohort ESPOIR, and 2) To assess the factors associated with the timing of bDMARD initiation.

Methods: In this national multicenter cohort, 813 adult patients with suspected or confirmed early RA were included between December 2002 and March 2005, and followed up during 10 years. In the present analysis, we considered only patients who were fulfilling the ACR-EULAR 2010 criteria for RA at baseline. The primary outcome was the time to initiation of a biologic DMARD, in months, since diagnosis. It was assessed by Cox model based survival analysis with time dependent covariates; the threshold used for $p$-value was 0.05 . Predictors colinearity was then assessed by adapted tests. All statistical analysis were done with $\mathrm{R}$ version 3.5.1.

Results: Among the 658 patients fulfilling the ACR-EULAR 2010 criteria for RA $(77 \%$ women, $52 \%$ smokers at baseline, mean-aged 48 at diagnosis, with positive RF in $46.6 \%$, positive ACPA in $43 \%$ and polyarticular presentation at baseline in $54.5 \%), 178$ patients $(31 \%, \mathrm{Cl} 95 \%=$ [27\%;34.7\%]) initiated a biologic DMARD during the 10-year follow-up (Figure 1). Variables associated with an earlier bDMARD initiation in the bivariate analysis were: 1) at baseline: younger age $(p=0.0016)$, younger age of first joint pain (0.0014), younger age of first joint swelling $(0.0014), 2)$ during the follow up: joint pain $(p<0.0001)$, high HAQ $(p<$ 